\title{
A retrospective hospital study of human cystic echinococcosis in Egypt
}

A. Kandeel, ${ }^{1,2}$ E.S. Ahmed, ${ }^{1}$ H. Helmy, ${ }^{1}$ M. El Setouhy, ${ }^{1}$ P.S. Craig ${ }^{3}$ and R.M.R. Ramzy ${ }^{1}$

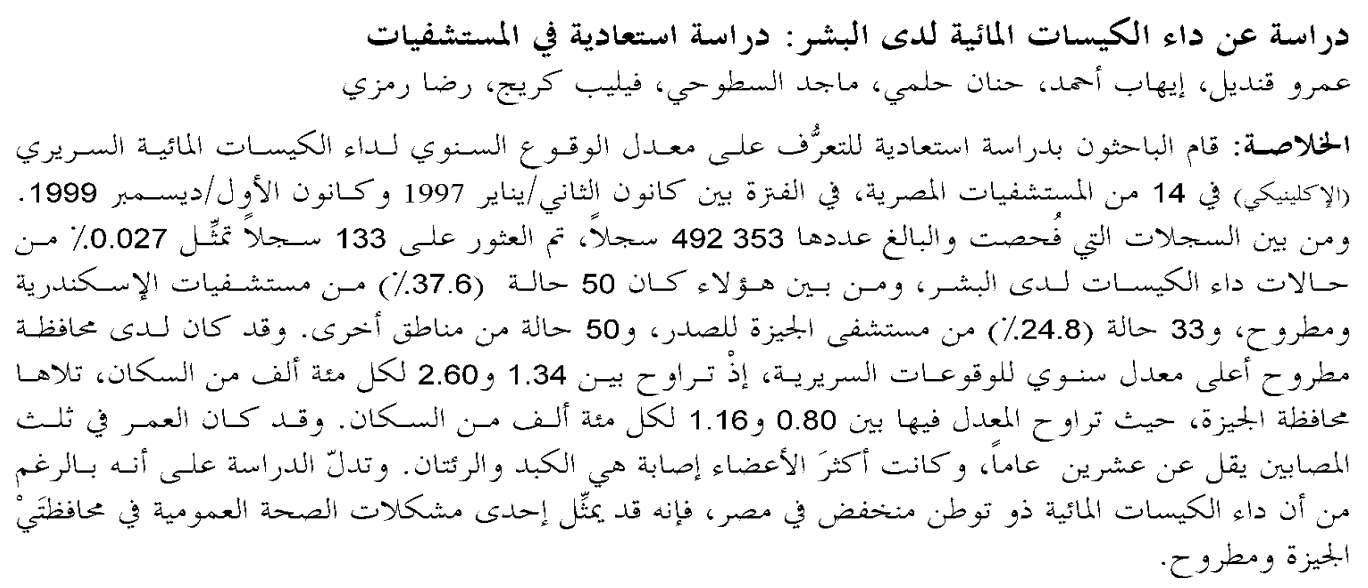

ABSTRACT We performed a retrospective study to determine annual clinical incidence of human cystic echinococcosis (CE) in 14 Egyptian hospitals between January 1997 and December 1999. From 492353 records examined, $133(0.027 \%)$ new human CE cases were recorded. Of these, $50(37.6 \%)$ were from Alexandria and Matrouh hospitals, $33(24.8 \%)$ from Giza Chest Hospital and 50 from other regions. Matrouh governorate had the highest annual clinical incidence (1.34-2.60 per 100000$)$ followed by Giza governorate $(0.80-1.16$ per 100000$)$. About a third of those affected were aged $\leq 20$ years. Liver and lungs were the organs most affected. Although human CE is of low endemicity in Egypt, it may represent a public health concern in Matrouh and Giza governorates.

\section{Etude hospitalière rétrospective de l'échinococcose kystique humaine en Egypte}

RESUME Nous avons réalisé une étude rétrospective dans 14 hôpitaux égyptiens entre janvier 1997 et décembre 1999 afin de déterminer l'incidence clinique annuelle de l'échinococcose kystique humaine. Parmi les 492353 dossiers examinés, $133(0,027 \%)$ nouveaux cas d'échinococcose kystique humaine ont été recensés. Cinquante $(50)$ de ces cas $(37,6 \%)$ ont été enregistrés dans les hôpitaux d'Alexandrie et de Matrouh, $33(24,8 \%)$ à l'hôpital cardiothoracique de Giza et 50 dans les hôpitaux d'autres régions. Le Gouvernorat de Matrouh avait la plus forte incidence clinique annuelle (1,34-2,60 pour 100000$)$ suivi par le Gouvernorat de Giza (0,80-1,16 pour 100000$)$. Environ un tiers des personnes affectées étaient âgées de 20 ans ou moins. Le foie et les poumons étaient les organes les plus touchés. Bien que l'Egypte soit un pays de faible endémicité de l'échinococcose kystique humaine, cette maladie peut représenter une préoccupation de santé publique dans les gouvernorats de Matrouh et de Giza.

${ }^{1}$ Research and Training Centre on Vectors of Diseases, Faculty of Science, Ain Shams University, Cairo, Egypt.

${ }^{2}$ Ministry of Health and Population, Cairo, Egypt.

${ }^{3}$ Biosciences Research Institute, University of Salford, Manchester, United Kingdom.

Received: 23/09/02; accepted: 06/05/03

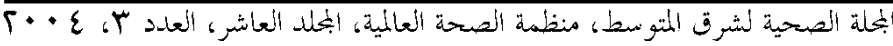




\section{Introduction}

Human cystic echinococcosis (CE) (cystic hydatidosis) is a chronic zoonotic disease that results from infection with the larval stage of the dog tapeworm, Echinococcus granulosus. The disease is highly endemic in most of the countries of the Mediterranean basin, including North Africa and the Middle East [1,2]. It has been reported as an important public health problem in Jordan, Libyan Arab Jamahiriya, Morocco, Tunisia, and Israel [3-7]. Thus, Egypt is surrounded by countries endemic for $\mathrm{CE}$, and several publications have recognized the existence of human $\mathrm{CE}$ cases among Egyptians [8-10]. Furthermore, CE has been documented by veterinarians in slaughtered camels (4.3\%) and sheep $(0.33 \%)$ in Egyptian abattoirs [11,12]. There is, however, little medical awareness or information regarding the endemicity of human $\mathrm{CE}$ in the country.

In human $\mathrm{CE}$, the liver is the main organ affected, followed by lung tissue, however, there is usually no direct parasitological evidence for the presence of cysts in organs or tissues. Indirect methods of diagnosis are, therefore, important and include imaging for detection of a space-occupying mass and serological techniques which require improved clinical and laboratory facilities [13]. Patients with hepatic CE frequently exhibit no symptoms because of the slow progression of the cysts [2]; therefore, they may only be discovered accidentally and frequently have complicated forms of the disease. Pulmonary hydatidosis may be fortuitously revealed during thoracic radiography. Surgery, chemotherapy (or a combination of both) and the PAIR technique (puncture, aspiration, injection, reaspiration) are the main forms of treatment of human CE [14,15].

Cystic echinococcosis is a disease of people living in rural areas, where pastoral livestock is predominant [10], but there appears to be no recognized area where CE transmission is intense in Egypt. Consequently, physicians in rural areas rarely consider $\mathrm{CE}$ in their differential diagnosis. Furthermore, medical administrations in rural areas are frequently inadequate and therefore consultation with experienced physicians is required. Cases with query diagnosis are usually referred to specialized Ministry of Health and Population (MOHP) hospitals or to major universities for conclusive diagnosis and intervention.

Accordingly, the objective of this retrospective study was to determine the annual clinical incidence of the disease in northern Egypt. In particular, we examined records in 14 hospitals, including university hospitals, MOHP specialized hospitals and referral hospitals covering the period January 1997 to December 1999.

\section{Methods}

The study was carried out at general and specialized hospitals of 3 universities (in Alexandria, Cairo and Giza governorates), the hospital of the Liver Institute (Menoufia University, in the Nile delta) and $10 \mathrm{MOHP}$ hospitals (6 chest and 4 general referral). The MOHP hospitals are located in Cairo, the Nile delta, North Sinai, and Matrouh governorate in the north-western part of Egypt. We reviewed inpatient records from all sites for the period January 1997December 1999. During the study period, with the exception of Kasr El Aini Hospital (Cairo University), none of the records were kept on computer, therefore, the medical records were searched manually by one of our teams. The review team consisted of a physician, who worked as project manager, along with 2 part-time health workers as reviewers. The physician was qualified for a minimum of 10 years.

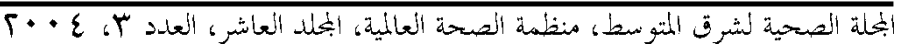


Each reviewer screened sets of 50 notes under supervision until they were judged to be fully conversant with the review process. Records that were suspected for CE were then reviewed by clinicians, who verified the final diagnosis.

As mentioned above, diagnosis of $\mathrm{CE}$ is usually based on imaging techniques with serological confirmation, and surgery, chemotherapy and the PAIR technique are the main forms of treatment. Hence, the criteria we used to assess the case records were indicative imaging techniques (X-ray, ultrasound, CT scan or MRI) or positive serological tests (indirect haemagglutination or enzyme-linked immunosorbent assay), along with treatment of the case with chemotherapy (albendazole), surgery or PAIR, and histopathology records of cysts or aspiration fluid. Sex, date of admission, date and place of birth, cyst location, and whether the infection was new or recurrent were recorded for all $\mathrm{CE}$ cases. We maintained patient confidentiality by using initials only for individual identification. Multiple admissions for the same patient were identified from admission dates, initials, age, sex and only the first admission of such cases was included in the analysis.

Since it was not feasible to include all hospitals and clinics that perform thoracic and abdominal surgery in each region covered in the study, we adjusted the annual clinical incidence of recorded cases to estimate adjusted incidence. This was done by dividing the recorded $\mathrm{CE}$ cases by the number of beds in the hospitals we studied then multiplying the outcome by the total number of hospital beds in each governorate.

For example, in Matrouh governorate, we only screened patient records in 2 hospitals (Matrouh General Hospital and Matrouh Chest Hospital) which have a total of 386 beds. However, we added 117 beds to compensate for other hospitals and clinics in the governorate that could specifically diagnose $\mathrm{CE}$ or perform surgery. In other words, beds in hospitals and clinics not involved with CE (e.g. psychiatry, maternity, child health) were excluded. Incidence was calculated as in the following example: for Matrouh governorate, 1997: 2 (no. of cases) divided by 386 (no. of beds in screened hospitals) multiplied by 503 (corrected no. of beds) $=2.6$ cases. This figure was used to estimate the annual incidence, i.e. $2.6 / 194019 \times 100000=1.34$.

\section{Results}

A total of 492353 patient files were examined and 133 accumulated new cases of human $\mathrm{CE}$ were recorded from 14 hospitals examined for the period January 1997 to December 1999 (Table 1). Giza Chest Hospital showed the highest CE rate for total admissions $(0.096 \%-0.160 \%)$ followed by Menoufia Liver Institute $(0.026 \%-$ $0.088 \%$ ).

Table 2 shows the estimated annual clinical incidence (per 100000 population) of $\mathrm{CE}$ for each governorate, based on $2.1 \%$ annual growth rate of estimated resident population in 1996. Matrouh governorate had the highest annual incidence, followed by Giza governorate. The calculated rates for Matrouh governorate were significantly higher than Giza governorate in years 1998 (Matrouh 1.97/100 000, Giza $\left.0.80 / 100000 ; \chi^{2}=7.27, P=0.013\right)$ and 1999 (Matrouh 2.60/100 000, Giza $\left.1.00 / 100000 ; \chi^{2}=3.99, P=0.040\right)$. The estimated annual clinical incidence of $\mathrm{CE}$ did not differ significantly within each governorate from one year to another except in Cairo governorate, where the incidence increased significantly from $0.05 / 100000$ in 1997 to $0.27 / 100000$ in $1999\left(\chi^{2}=4.59\right.$, $P=0.03$ ).

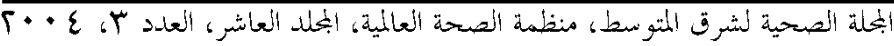




\begin{tabular}{|c|c|c|c|c|}
\hline \multirow[t]{2}{*}{ Hospital name (geographical region) } & \multirow[t]{2}{*}{ Year } & \multirow{2}{*}{$\begin{array}{l}\text { Total no. cases } \\
\text { admitted }\end{array}$} & \multicolumn{2}{|c|}{ Hydatid cyst cases } \\
\hline & & & & \\
\hline \multirow[t]{3}{*}{ Ain Shams University Hospital (Cairo) } & 1997 & 36408 & 1 & 0.003 \\
\hline & 1998 & 36735 & 3 & 0.008 \\
\hline & 1999 & 38294 & 7 & 0.018 \\
\hline \multirow[t]{3}{*}{ Kasr El Aini Hospital, Cairo University (Giza) } & 1997 & 50001 & 10 & 0.020 \\
\hline & 1998 & 51573 & 9 & 0.017 \\
\hline & 1999 & 52019 & 5 & 0.010 \\
\hline \multirow[t]{3}{*}{ Abassia Chest Hospital (Cairo) } & 1997 & 5941 & 1 & 0.017 \\
\hline & 1998 & 6438 & 2 & 0.031 \\
\hline & 1999 & 6362 & 4 & 0.063 \\
\hline \multirow[t]{3}{*}{ Giza Chest Hospital (Giza) } & 1997 & 7492 & 12 & 0.160 \\
\hline & 1998 & 7255 & 7 & 0.096 \\
\hline & 1999 & 8781 & 14 & 0.159 \\
\hline \multirow[t]{3}{*}{ Menoufia Liver Institute (Nile delta) } & 1997 & 3402 & 3 & 0.088 \\
\hline & 1998 & 3867 & 1 & 0.026 \\
\hline & 1999 & 4112 & 3 & 0.073 \\
\hline \multirow[t]{3}{*}{ Menoufia Chest Hospital (Nile delta) } & 1997 & 964 & 0 & - \\
\hline & 1998 & 989 & 0 & - \\
\hline & 1999 & 1041 & 0 & - \\
\hline \multirow[t]{3}{*}{ Alexandria University Hospital (Alexandria) } & 1997 & 26451 & 13 & 0.049 \\
\hline & 1998 & 27447 & 12 & 0.044 \\
\hline & 1999 & 27297 & 16 & 0.059 \\
\hline \multirow[t]{3}{*}{ Alexandria Chest Hospital (Alexandria) } & 1997 & 3927 & 0 & - \\
\hline & 1998 & 4036 & 0 & - \\
\hline & 1999 & 3891 & 0 & - \\
\hline \multirow[t]{3}{*}{ Matrouh General Hospital (north-west Egypt) } & 1997 & 8649 & 2 & 0.023 \\
\hline & 1998 & 7976 & 3 & 0.038 \\
\hline & 1999 & 8685 & 3 & 0.035 \\
\hline \multirow[t]{3}{*}{ Matrouh Chest Hospital (north-west Egypt) } & 1997 & 829 & 0 & - \\
\hline & 1998 & 792 & 0 & - \\
\hline & 1999 & 947 & 1 & 0.106 \\
\hline \multirow[t]{3}{*}{ El Saloum General Hospital (north-west Egypt) } & 1997 & 731 & 0 & - \\
\hline & 1998 & 694 & 0 & - \\
\hline & 1999 & 674 & 0 & - \\
\hline
\end{tabular}

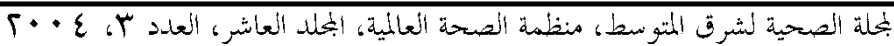




\begin{tabular}{lcccc}
\hline Eastern Mediterranean Health Journal, Vol. 10, No. 3, 2004 & 353 \\
\hline $\begin{array}{l}\text { Table 1 Identification of human hydatid cyst cases in records of 14 hospitals in Egypt during } \\
\text { the period 1997-1999 (concluded) }\end{array}$ & Year & $\begin{array}{c}\text { Total no. cases } \\
\text { admitted }\end{array}$ & $\begin{array}{c}\text { Hydatid cyst cases } \\
\text { No. }\end{array}$ & \% \\
\hline Hospital name (geographical region) & 1997 & 4752 & 1 & 0.021 \\
\hline El Suez General Hospital (eastern Egypt) & 1998 & 5016 & 0 & - \\
& 1999 & 4421 & 0 & - \\
North Sinai Hospital (north-east Egypt) & 1997 & 10922 & 0 & - \\
& 1998 & 10241 & 0 & - \\
North Sinai Chest Hospital (north-east Egypt) & 1999 & 10789 & 0 & - \\
& 1997 & 471 & 0 & - \\
Total & 1998 & 458 & 0 & - \\
\hline
\end{tabular}

All age groups and both sexes were well represented among patients with CE (Table 3). Approximately one third (45 cases) of the CE cases were $\leq 20$ years of age. Of these, $19(42.2 \%)$ were from hospitals in Giza governorate and $18(40.0 \%)$ from hospitals in Alexandria and Matrouh governorates.

Of the 133 cases of human CE, 79 (59.4\%) people had surgical interference. Of these, $18(22.8 \%)$ cases had been confirmed pathologically. The remaining 54 (40.6\%) cases received medical treatment; they were diagnosed based on serological tests and imaging techniques.

Hydatid cysts occurred most commonly in the liver and the lungs, either singly (54 and 52 respectively) or in conjunction with other organs (24 and 11 respectively). A total of 24 cases involved infection in $>1$ organ (Table 4).

\section{Discussion}

Egypt is recognized to be endemic for parasitic diseases such as schistosomiasis, fi- lariasis and amoebiasis. Cystic echinococcosis, however, is not currently a wellknown medical condition, nor is it considered to be of public health importance; it is not a notifiable disease and there are no surveillance data available for the country. Our study was carried out to determine whether infection with CE represents a public health threat to residents of certain areas and to identify regions with high parasite transmission. Our data clearly confirm the low endemicity of the disease in northern Egypt, however the data indicate that the incidence of $\mathrm{CE}$ was relatively high in the western governorate of Matrouh, near the Libyan border, decreasing towards the east, and virtually disappearing in the most easterly parts of the country.

The calculated CE incidence for Giza governorate was unexpectedly high. Several factors could account for this finding. Firstly, major hospitals like Cairo University hospitals, located in Giza, do not just serve residents of Giza governorate: as there are no hospitals specialized in treating hydatidosis, patients seeking high quality

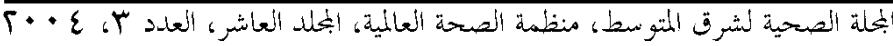




\begin{tabular}{|c|c|c|c|c|}
\hline Governorate & $Y{ }^{a}$ & Population $^{b}$ & No. & $\begin{array}{l}\text { ases } \\
\text { icidence }\end{array}$ \\
\hline \multirow[t]{3}{*}{ Matrouh } & 1997 & 194019 & 2 & 1.34 \\
\hline & 1998 & 198181 & 3 & 1.97 \\
\hline & 1999 & 202432 & 4 & 2.60 \\
\hline \multirow[t]{3}{*}{ Alexandria } & 1997 & 3515238 & 13 & 0.70 \\
\hline & 1998 & 3590641 & 12 & 0.65 \\
\hline & 1999 & 3667662 & 16 & 0.85 \\
\hline \multirow[t]{3}{*}{ Menoufia } & 1997 & 2683728 & 3 & 0.83 \\
\hline & 1998 & 2741295 & 1 & 0.27 \\
\hline & 1999 & 2800097 & 3 & 0.80 \\
\hline \multirow[t]{3}{*}{ Giza } & 1997 & 4554464 & 22 & 1.16 \\
\hline & 1998 & 4652160 & 16 & 0.80 \\
\hline & 1999 & 4751950 & 19 & 1.00 \\
\hline \multirow[t]{3}{*}{ Cairo } & 1997 & 7450857 & 2 & 0.05 \\
\hline & 1998 & 7610682 & 5 & 0.13 \\
\hline & 1999 & 7773934 & 11 & 0.27 \\
\hline \multirow[t]{3}{*}{ Suez } & 1997 & 394063 & 1 & 0.40 \\
\hline & 1998 & 402516 & 0 & - \\
\hline & 1999 & 411150 & 0 & - \\
\hline \multirow[t]{3}{*}{ North Sinai } & 1997 & 121111 & 0 & - \\
\hline & 1998 & 123709 & 0 & - \\
\hline & 1999 & 126363 & 0 & - \\
\hline
\end{tabular}

${ }^{a}$ Number of beds remained the same in all 3 years. ${ }^{b}$ Populations were calculated based on $2.1 \%$ annual growth rate of estimated resident population in 1996.

medical care would choose hospitals such as these, which are known for good diagnosis and intervention. One of the limitations of our study is that the geographic location of residence and occupation at the time of admission were not always recorded in the files of many patients. Thus, some of the CE patients at hospitals in Giza could have been residents of other regions. Secondly, there is a large market for camels
Table 3 Age and sex distribution of cases with human cystic hydatidosis

\begin{tabular}{lrrrr}
\hline $\begin{array}{l}\text { Age group } \\
\text { (years) }\end{array}$ & Male & Female & \multicolumn{2}{c}{ Total } \\
No. & $\%$ \\
\hline$\leq 10$ & 6 & 3 & 9 & 6.8 \\
$11-20$ & 19 & 17 & 36 & 27.1 \\
$21-30$ & 15 & 16 & 31 & 23.3 \\
$31-40$ & 16 & 14 & 30 & 22.6 \\
$>40$ & 13 & 14 & 27 & 20.3 \\
Total & 69 & 64 & 133 & 100 \\
\hline
\end{tabular}

imported from Sudan (where the disease is prevalent) in Imbaba, Giza, where camels are kept before being slaughtered in an abattoir in the vicinity. Haridy, Ibrahim and Morsy reported that $4.0 \%-7.5 \%$ of camels slaughtered in Egypt had CE lung infection [11], and Ibrahem and Craig recorded a prevalence of $48 \%$ in Libyan camels [16]. It is possible that camels play an important role in the epidemiology of echinococcosis and hydatidosis in Giza governorate. Finally, since Giza Chest Hospital showed the highest incidence of $\mathrm{CE}$, using such a figure for the assessment of the overall incidence rate for this region could have resulted in overestimation of the calculated incidence for Giza governorate.

In general, retrospective hospital surveys have been criticized for not providing precise estimates of disease incidence as not all hospitals in a particular region or district are included in the study, and the population is calculated rather than based on actual census. Furthermore, retrospective hospital survey data on human CE cannot give an accurate picture of the prevalence of infection. A certain number of cases are not seen in hospitals because the infection is asymptomatic or does not require surgical intervention, and some data are not

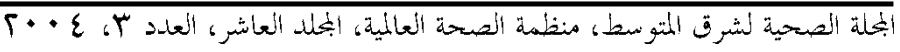



Table 4 Distribution and treatment of hydatid cysts according
to location

\begin{tabular}{|c|c|c|c|c|c|}
\hline \multirow{2}{*}{$\begin{array}{l}\text { Location } \\
\text { of cyst }\end{array}$} & \multicolumn{2}{|c|}{ Cases } & \multicolumn{3}{|c|}{ No. treated cases } \\
\hline & No. & $\%$ & Surgery & PAIR & Chemotherapy \\
\hline Multiple sites $^{\mathrm{a}}$ & 24 & 18.0 & 1 & $2^{\mathrm{b}}$ & 21 \\
\hline \multicolumn{6}{|l|}{ Single site } \\
\hline Liver & 54 & 40.6 & 25 & $13^{b}$ & 16 \\
\hline Lung & 52 & 39.1 & 51 & - & 1 \\
\hline Spleen & 2 & 1.5 & 1 & - & 1 \\
\hline Brain & 1 & 0.8 & 1 & - & - \\
\hline Total & 133 & 100 & 79 & 15 & 39 \\
\hline
\end{tabular}

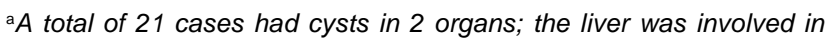
all cases along with lung (11), spleen (5), kidney (4) and brain (1). Three cases had > 2 organs involved: the liver, spleen and kidney were affected in one case; the liver, spleen, kidney and the pancreas in the second case; and the liver, spleen and the pectoralis major muscle in the third case.

${ }^{b}$ Cases received additional chemotherapy.

$P A I R=$ puncture, aspiration, injection, reaspiration.

available in the files. However, despite such limitations, careful examination of hospital records provides a useful indication of infection expressed as annual rate of hospital cases. It can give an indication of the public health importance of a disease and, when done continuously over many years, detects regional changes in incidence of infection [17].

In this study, we used a formula based on number of hospital beds to correct for the underestimation of annual rates for hospitals that were not included in the survey. It was of especial interest that Matrouh governorate, which is adjacent to the Libyan border, had the highest annual incidence. The Libyan Arab Jamahiriya is known to have a high prevalence of human CE [5].

The finding that all age groups, including children and young adults, were well represented in the confirmed CE cases implies that both adults and children are susceptible to infection. Since about one-third of the cases were $\leq 20$ years of age, it suggests that active transmission occurs and that the disease may be on the increase, especially in Giza and the western governorates, demonstrating the potential public health importance of $\mathrm{CE}$ and that consideration should be given to the introduction of prevention and control measures in these regions.

In conclusion, this study proved highly useful in determining the annual incidence of hospitalized CE cases. It identified 2 areas, Matrouh and Giza governorates, where the disease could be of public health importance and CE should perhaps be a notifiable disease in these regions.

\section{Acknowledgements}

The authors wish to thank the administration authorities of the hospitals included in the study for their cooperation throughout

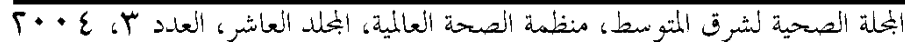


the study period. The study was supported by the European Commission's Scientific and Technological Cooperation with Devel- oping Countries (INCO-DC) programme, No. IC18CT980354.

\section{References}

1. Matossian RM, Rickard MK, Smyth JD. Hydatidosis: a global problem of increasing importance. Bulletin of the World Health Organization, 1977, 55(4): 499-507.

2. Andersen FL. Introduction to cystic echinococcosis and description of cooperative research project in Morocco. In: Andersen FL, Ouhelli $\mathrm{H}$, Kachani M, eds. Compendium on cystic echinococcosis in Africa and Middle Eastern countries with special reference to Morocco. Provo, Utah, Brigham Young University, 1997:3-17.

3. Pandey VS, Ouhelli H, Moumen A. Epidemiology of hydatidosis/echinococcosis in Quarzazate, the pre-Saharan region of Morocco. Annals of tropical medicine and parasitology, 1988, 82(5): 461-70.

4. Bchir A et al. Echotomographic and serological population-based study of hydatidosis in central Tunisia. Acta tropica, 1991, 49(2):149-53.

5. Shambesh MK et al. A high prevalence of cystic hydatid disease in North Africa. Annals of tropical medicine and parasitology, 1997, 91(8):957-9.

6. Kamhawi S. A retrospective study of human cystic echinococcosis in Jordan. Annals of tropical medicine and parasitology, 1995, 89(4):409-14.

7. Nahmias $\mathrm{J}$ et al. High prevalence of human hydatid disease (echinococcosis) in communities in northern Israel: epidemiologic studies in the town of Yirka. Acta tropica, 1992, 50(1):1-10.

8. Kaddah $\mathrm{MH}$ et al. Evaluation of different immunodiagnostic techniques for diag- nosis of hydatidosis in Egypt. Journal of the Egyptian Society of Parasitology, 1992, 22(3):653-65.

9. Ramzy RMR et al. An enzyme-linked immunosorbent assay for detection of IgG1 antibodies specific to human cystic echinococcosis in Egypt. Tropical medicine and international health, 1999, 4(9):616-20.

10. Ramadan NI, el Damaty SI. A preliminary screening study of human cystic echinococcosis in Cairo slaughterhouse personnel. Journal of the Egyptian Society of Parasitology, 2000, 30(1):329-39.

11. Haridy FM, Ibrahim BB, Morsy TA. Studies on hydatidosis in slaughtered camels in Egypt. Journal of the Egyptian Society of Parasitology, 1998, 28(3): 673-81.

12. Haridy FM, Ibrahim BB, Morsy TA. Sheep-dog-man. The risk zoonotic cycle in hydatidosis. Journal of the Egyptian Society of Parasitology, 2000, 30(2): 423-30.

13. Craig PS, Rogan MT, Allan JC. Detection, screening and community epidemiology of taeniid cestode zoonosis: cystic echinococcosis, alveolar echinococcosis and neurocysticercosis. Advances in parasitology, 1996, 38:169-250.

14. Bastid $C$ et al. Percutaneous treatment of hydatid cysts under sonographic guidance. Digestive diseases and sciences, 1994, 39:1576-80.

15. Eckert JP et al., eds. WHO/OIE manual on echinococcosis in humans and animals: a public health problem of global concern. Paris, World Health Organiza-

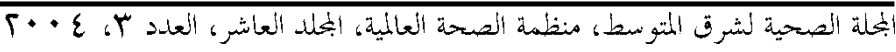


tion \& World Organization for Animal Health, 2001.

16. Ibrahem MM, Craig PS. Prevalence of cystic echinococcosis in camels (Camelus dromedarius) in Libya. Journal of helminthology, 1998, 72(1):27-31.

17. Schantz PM. Sources and uses of surveillance data for cystic echinococcosis.
In: Andersen FL, Ouhelli H, Kachani M, eds. Compendium on cystic echinococcosis in Africa and Middle Eastern countries with special reference to Morocco. Provo, Utah, Brigham Young University, 1997:72-84.

\section{2nd International Symposium on "Recent Advances in Surgery"}

The Department of Surgery of Riyadh Armed Forces Hospital is organizing the 2nd International Symposium on "Recent Advances in Surgery" from 10 to 12 December 2005/08-10 Dhu Al Qa'dah 1426. The symposium will be an opportunity for colleagues throughout the Kingdom, the region and beyond to meet, share and exchange their collective knowledge. The deadline for submission of abstracts is 30 September 2005 .

Further information can be obtained from: The Organizing Committee, Department of Surgery, Riyadh Armed Forces Hospital, PO Box 7897, Riyadh 11159, Saudi Arabia.

Tel Mo.: +966-1-477-7714 Extension 5287

Fax Mo.: +966-1-476-0853

Email: generalsurgery@rkh.med.sa

Website: http://www.rkh.med.sa/

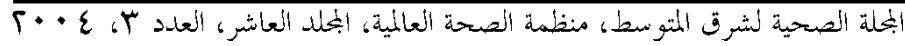

